\title{
Estradas-parque: Um estudo comparativo no intuito de definições para a experiência turística brasileira ${ }^{1}$
}

\author{
Park roads: \\ A comparative study for definitions for a Brazilian touristic experience
}

\section{Carreteras-parque: Un estudio comparativo con el intuito de definiciones para la experiencia turística brasileña}

\author{
Luciano Torres Tricárico ${ }^{2}$ \\ Josildete Pereira de Oliveira ${ }^{3}$ \\ Diva de Mello Rossini ${ }^{4}$ \\ Débora Ioná Carvalho 5
}

Resumo: A configuração de estradas-parque na experiência brasileira é muito recente. Mesmo assim ela é precursora como fato mundial, principalmente em relação aos avanços de uma legislação que pode amparar esta manifestação espacial em prol da proteção de um corredor ecológico e com usos turísticos; trata-se da consideração da categoria de estradas-parque no Sistema Nacional de Unidades de Conservação

\footnotetext{
${ }^{1}$ Artigo oriundo de pesquisa financiada pelo Programa Artigo 170 do Governo do Estado de Santa Catarina durante os anos de 2010 e 2011. Bem como a referida pesquisa integrou um trabalho maior desenvolvido entre 2008 e 2010 com financiamento do CNPq, com o título "Análise do litoral sul de Balneário Camboriú, SC: um estudo da transformação da paisagem da Rodovia Interpraias e do turismo". Outras partes desta pesquisa já foram publicadas.

${ }^{2}$ Doutor em Projeto, Espaço e Cultura e Mestre em Estruturas Ambientais Urbanas pela Universidade de São Paulo. Graduado em Arquitetura e Urbanismo pela Universidade de São Paulo. Pesquisador junto ao programa de mestrado em Turismo e Hotelaria e docente do Curso de Arquitetura e Urbanismo e Design de Interiores da Universidade do Vale do Itajaí. Coordenador do Laboratório de Paisagismo Aplicado (LaPa), da Universidade do Vale do Itajaí. E-mail: tricarico@univali.br

${ }^{3}$ Doutora em Geografia pela Université de Caen Basse, Normandie, França. Mestre em Natureza, Meio Ambiente, Sociedade pela Université de Caen Basse, Normandie, França. Graduada em Arquitetura e Urbanismo pela Universidade Federal da Bahia. Coordenadora do Grupo de Pesquisa Paisagem e Morfologia do Ambiente Urbano. Pesquisadora do Laboratório de Paisagismo Aplicado (LaPa), da Universidade do Vale do Itajaí. E-mail: joliveira@univali.br

${ }^{4}$ Doutoranda em Administração e Turismo pela Universidade do Vale do Itajaí (UNIVALI). Mestre em Engenharia de Produção pela Universidade Federal de Santa Catarina (UFSC). Graduada em Arquitetura e Urbanismo pela Universidade do Vale do Itajaí. Docente e pesquisadora do Curso de Arquitetura e Urbanismo da Universidade do Vale do Itajaí. Coordenadora dos Cursos de Arquitetura e Urbanismo, Design de Interiores e Técnico em Paisagismo da Universidade do Vale do Itajaí. E-mail: divarossini@univali.br

${ }^{5}$ Discente do Curso de Arquitetura e Urbanismo da Universidade do Vale do Itajaí. Bolsista do Programa Artigo 170 do Governo do Estado de Santa Catarina em 2010.E-mail: iona.carvalho@hotmail.com
} 
(SNUC). Porém, comparando-se com a experiência estrangeira, essencialmente a canadense e a norteamericana, percebe-se um descompasso nos ganhos que a efetivação de uma estrada-parque pode ocasionar para o planejamento ambiental e do turismo no Brasil. O método interpretativo desta pesquisa se apoia na Semiótica de Charles Sanders Peirce, destacando-se o papel da representação como eleição de signos que carregam ideologias do emissor. Diferentes modos de representação de estradas-parque podem revelar uma "matriz" de conteúdos comuns, denotados na experiência estrangeira ou nacional, e entre as duas; podendo-se disto interpretar características que as identificam. Para tanto, a metodologia procura estudar alguns casos já destacáveis de estradas-parque no Brasil e no exterior, com o intuito de definir parâmetros específicos entre um caso e outro, bem como elementos comuns entre os dois casos.

Palavras-chave: Turismo; Estradas-parque; Paisagismo; Planejamento ambiental.

Abstract: The configuration of roads park on the Brazilian experience is very recent. Yet it is a precursor for a fact the world, especially regarding the progress of legislation that can support this demonstration space to promote the protection of an ecological corridor with tourist uses, it is the account of category road park in the National System of Conservation Units (SNUC). However, comparing with the foreign experience, mainly Canadian and American, we find a mismatch in the gains that the realization of a park road can lead to environmental planning and of the tourism in Brazil. The interpretive method of this research is based on Semiotics by Charles Sanders Peirce, highlighting the role of representation as the election of two signs bearing the ideologies of the issuer. Different modes of representation road park may reveal a "matrix" of common content, denoted in foreign or national experience, and between the two, it could be interpreted characteristics that identify them. For this, the methodology is to study the cases of road park in Brazil and abroad, in order to define specific parameters from one case to another, as well as common elements between the two cases.

Key words: Tourism; Park roads; Landscaping; Environmental planning.

Resumen: La configuración de las carreteras-parque en la experiencia brasileña es muy reciente. Pero es una experiencia precursora de hecho en el mundo, especialmente en relación con el progreso de la legislación que puede apoyar este espacio para la promoción de la protección de un corredor ecológico y los usos turísticos - la consideración de la categoría de carreteras-parque en el Sistema Nacional de Unidades de Conservación (SNUC). Sin embargo, en comparación con la experiencia extranjera, en su mayoría canadienses y estadounidenses, la experiencial brasileña se muestra con una brecha en los ingresos que la realización de una carretera-parque puede conducir a la planificación ambiental y el turismo en Brasil. El método interpretativo de esta investigación se basa en la semiótica de Charles Sanders Peirce, destacando el papel de los signos de representación y elección que llevan las ideologías del emisor. Diferentes modos de representación de la carretera-parque puede revelar una "matriz" de contenido común, que se denota en la experiencia extranjera o nacional, y entre los dos; y podemos interpretar estas características que las identifican. Para esto, la metodología utilizada fue el estudio de algunos casos en Brasil y en el extranjero, con el fin de definir los parámetros específicos de un caso a otro, así como los elementos comunes entre ellos.

Palabras clave: Turismo; Carreteras-parque; Paisajismo; Planificación ambiental.

\section{INTRODUÇÃO}

Uma paisagem de ecossistemas degradados se configura em um sistema de grande fragilidade ou instabilidade nos quais os efeitos ou impactos ambientais serão mais consideráveis conforme (e geralmente) a ação antrópica, daí se abrindo a possibilidade de cadeias de efeito cumulativo prejudiciais ao meio natural ou construído, bem como ao ser humano. Tal 
compreensão da convergência entre os processos naturais e antrópicos é uma das essências do planejamento ambiental e da paisagem. Ora, o planejamento da paisagem e do meio natural não é novidade nenhuma; ele remonta às antigas civilizações da China, Oriente Médio ou Egito, seja com objetivos agrícolas ou sociais. No entanto, a novidade está em considerar os processos naturais dotados de inabilidades, escassez e até mesmo serem totalmente suprimidos.

Desta forma, até recentemente, os conceitos de planificação, desenho e uso do ambiente sugeriam que a paisagem é totalmente controlada pelo homem; porém a experiência demonstrou que isto não é absoluto (segundo as teses de Michel Laurie), porque há uma dialética nesta relação entre homem e natureza. É a atual fase da consciência ecológica preconizada na arquitetura paisagística como um importante instrumento de trabalho perante o ambiente, e intensamente vinculada ao processo de reconhecimento e valorização dos empreendimentos humanos em sua espacialização.

Nesta nova consciência ecológica, o território se especializa e instala um novo sistema da natureza como seu conjunto de recursos naturais potencialmente utilizáveis. A natureza passa a ser considerada como um sistema social de lugares; por exemplo: os locais de produção se transformam em bases para instalação de infraestruturas nas quais o processamento da paisagem passa a anteceder a própria produção. Uma nova consciência ecológica expande uma nova comunicação, pesquisa e consumo do lazer e turismo em áreas restabelecidas ou preservadas/conservadas, criando-se circuitos produtivos em suportes espaciais ao mesmo tempo em que são círculos de cooperação entre as necessidades do capital, geração de emprego e renda e natureza; ou ainda: uma consciência da tecnoesfera, nos termos de Santos (1996).

Mas esta nova condição somente se efetivou no final da década de 1960 do século XX quando os paradigmas da sociedade industrial foram questionados. Dentre as causas deste questionamento, pode ser verificada a degradação de ecossistemas naturais, implicando uma série de problemas ambientais que afetavam diretamente os seres humanos. Neste sentido, este artigo pretende expor um destes problemas: a necessidade de corredores verdes e ecológicos para a migração de organismos vivos, concomitantes com usos antrópicos essencialmente turísticos. Portanto, nesta condição, estes corredores surgem também como oportunidade ao ócio, lazer e turismo; e devem ser acessíveis para toda sociedade - eis as vias-parque e estradasparque como possível manifestação espacial desta condição de corredor verde ecológico.

Para tanto, deve-se considerar que o método interpretativo não se inicia com a formulação de uma teoria ambientalista que é aplicada ao objeto no intuito de deduzir alguma relação teórica a partir da experiência concreta de estradas-parque; mas, parte-se do objeto estudado como gerador de novas interpretações. Em determinados momentos da pesquisa ocorreu uma simultaneidade entre objeto estudado e teoria; deste modo é que a leitura bibliográfica serviu para estimular a interpretação, entendendo-a como repertório informacional e não como mecanismo justificativo. A dedução, então, se junta à experiência empírica do objeto estudado para possibilitar a verificação de sua formulação hipotética que pôde explanar uma nova hipótese. Fez-se, com isto, a necessidade da leitura ambiental dos objetos de estudo, dos elementos 
comunicativos e icônicos (representações) como recortes desta pesquisa (essencialmente encontrados em propaganda turística de estradas-parque).

A leitura se deu inicialmente com a contextualização do material iconográfico e dos espaços elencados e representados em material imagético e comunicativo de diferentes projetos de estradas-parque no Brasil e no exterior, essencialmente coletados em divulgação de propaganda turística em sítios eletrônicos (sites da internet). De modo que houve uma "varredura" de fontes iconográficas e materiais que foram julgados como documento a ser analisado, em razão da pertinência do tempo e lugar deste estudo; bem como por limitações de pesquisa in loco, considerando-se custos, prazos e viabilidade deste trabalho.

Foram úteis os estudos de Peirce (1975), filósofo norte-americano considerado o fundador da Semiótica norte-americana. Com ele, a lógica da representação se dá por signos que substituem o objeto, não propriamente em todos os seus aspectos, mas naqueles que se quer representar. Na seleção do que se pretende representar, é possível identificar uma intelecção, por parte do sujeito emissor, em propor ideologias. Estes processos de representação, tanto como emissor ou receptor, revelam o repertório cultural dos sujeitos envolvidos e produzem significados que, associados, podem desmembrar, alterar, reconsiderar as hipóteses formuladas no início e permitir possíveis generalizações ou interpretações que estão na raiz da linguagem espacial que é plurisignificativa.

Para tanto, a metodologia que amparou o método interpretativo compreendeu: montagem de bibliografia e material iconográfico; leitura de bibliografia e documentação; sistematização da bibliografia, documentação e material iconográfico e interpretação crítica.

É importante ressaltar que a sistematização dos dados coletados e analisados foi amparada por um roteiro de diagnóstico das áreas estudadas em função de uma experiência acumulada nas disciplinas de paisagismo do curso de Arquitetura e Urbanismo da Universidade do Vale do Itajaí (UNIVALI) $^{6}$ e de uma fundamentação teórica própria à disciplina do Paisagismo e do Planejamento Ambiental, tais como Franco (1997), Macedo e Sakata (2010) e Kliass (1993). Este roteiro procura encerrar aspectos relativos às peculiaridades de um corredor ecológico, bem como um programa mínimo que se constitui já codificado para interpretar uma área como um sistema de lazer; portanto de uso como parque ou estrada-parque. Assim sendo:

1. Entorno: polos geradores de tráfego a partir dos principais equipamentos urbanos; usos do solo e turísticos; formas de transporte; permeabilidade e acessibilidade à área de parque; unidade do entorno (massa de edificações, linguagens arquitetônicas, tipologias).

2. Equipamentos e mobiliário urbano: adequabilidade (utilização, quantidade, funcionalidade, distribuição); interferência no conjunto; estética/design.

3. Sinalização/Comunicação visual: identificação (espacial, por atividade, direcionamento, design).

4. Fauna e flora: elenco vegetal e animais existentes.

\footnotetext{
${ }^{6}$ O referido roteiro foi desenvolvido como auxílio aos alunos no levantamento de campo nas disciplinas de Paisagismo I, Paisagismo II e Paisagismo III do Curso de Arquitetura e Urbanismo da Universidade do Vale do Itajaí (UNIVALI).
} 


\section{ESTRADAS-PARQUE COMO ESTUDOS DE CASO}

\section{Pantanal (MS, Brasil)}

A estrada compreende as rodovias estaduais MS-184 e MS-228, sendo considerada uma unidade de conservação pelo governo de Mato Grosso do Sul em 1993. O traçado remonta às rotas originais das grandes boiadas e caminhos naturais do Pantanal. Foi traçada originalmente por Marechal Cândido Rondon ao trazer a rede de telégrafos para a região. Sua construção só foi possível com aterros que variam de um a três metros que procuram garantir o deslocamento em qualquer época do ano; porém essa condição é comprometida nas cheias mais intensas (Estrada Parque Pantanal, 2010). Mas a própria cheia acaba por se tornar também uma forma de atração, segundo muitas imagens de divulgação turística (Figura 1).

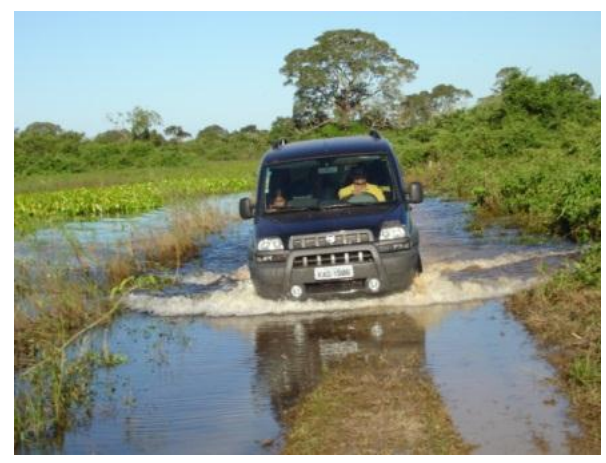

Figura 1. Parte da Estrada-parque do Pantanal inundada em épocas de cheia

Fonte: www.interativapantanal.com.br/admin

\section{Entorno}

- Polos geradores de tráfego: considera-se a cidade de Corumbá, por onde se tem verificado as principais partidas turísticas.

- Usos: a única área urbanizada próxima à estrada-parque é a cidade de Corumbá. Ao longo da estrada existe apenas o setor de serviços hoteleiros com pousadas e hotéis-fazenda (predominantemente na porção sul da estrada).

- Transporte: nota-se ausência de transporte coletivo destinado para toda via. O automóvel de passeio, geralmente para os esportes de aventura, apresenta-se com frequência nas imagens de divulgação.

- Permeabilidade e acessibilidade: existem duas opções para percorrer a estrada-parque, partindo-se de Campo Grande, entra-se pelo Buraco da Piranha onde existe um Posto da Polícia Militar Ambiental, próximo ao Morro do Azeite; e pode partir de Corumbá, por um lugarejo conhecido como Lampião Aceso (Estrada Parque Pantanal, 2010).

- Unidade do entorno: a constância de imagens com apelo à natureza realça este modo de vocação turística ao longo da estrada. Pode-se interpretar também que o mote da natureza é 
uma pretensa construção da imagem desta destinação turística que só foi possível em razão daquela realidade exuberante de paisagem.

Equipamentos e mobiliário urbano

- A estrada-parque é bastante conhecida por locais onde se pratica a pesca esportiva, há a presença de equipamentos destinados à fruição da fauna e flora. Possui 70 pontes de madeira onde se observa grande número de animais e aves. Antigas sedes de fazendas de gado conciliam as atividades de pecuária e ecoturismo (Estrada Parque Pantanal, 2010). A coleta de imagens de divulgação turística não apresentou relevância quanto ao mobiliário urbano em seus aspectos de adequação e quantidade.

\section{Sinalização/Comunicação visual}

- Imagens coletadas apresentam sinalização quanto à fauna e indicativas de equipamentos de serviços de hotelaria particulares. Não foi encontrada informação acerca de outro tipo de sinalização; mas é possível arriscar que há sinalização de trânsito.

\section{Fauna e flora}

- Há vegetação rasteira com milhares de ribeirões (corixos) e lagos naturais (Estrada Parque Pantanal, 2010). Na flora da região pantaneira as espécies mais comuns florescem em diferentes épocas do ano, sendo um atrativo para o deleite visual do turista, portanto independente de sazonalidades como atrativo.

\section{Itacaré (BA, Brasil)}

Tal como a Estrada-parque do Pantanal, a estrada-parque de Itacaré na Bahia (unindo Ilhéus a Itacaré, passando por Serra Grande) também foi aberta em função da rede de telégrafos durante a Segunda Guerra Mundial. Concluída em 1998, conta com 65 km de extensão (Figura 2), sendo a primeira rodovia do Brasil que contou com um monitoramento ambiental em toda sua fase de obras (Esportes e Lazer, 2010).

\section{Entorno}

- Polos geradores de tráfego: a estrada-parque tem várias praias ao longo de sua extensão que atraem diversos turistas; também trilhas, cachoeiras, pousadas, arborismo, esportes radicais, entre outros relacionados à natureza (Esportes e Lazer, 2010).

- Usos: as áreas urbanizadas se encontram nas extremidades da estrada com as cidades de Itacaré e Ilhéus. As imagens de divulgação denotam um uso turístico do lazer de "sol e mar", amparado por resorts com forte apelo a uma natureza tropical e luxuriante.

- Transporte: há transporte coletivo por toda a via unindo as duas cidades de llhéus e Itacaré.

- Permeabilidade e acessibilidade: os acessos são pelas duas cidades de limite da estrada, por 
uma rodovia que passa pela Lagoa Encantada, próxima a Ilhéus; e pela rodovia BA-262 (Esportes e Lazer, 2010). Ao longo da estrada há um grande fluxo turístico desordenado, em função da falta de estrutura e há a especulação imobiliária como um fato preocupante, uma vez que não foi estabelecida nenhuma política sobre a proteção e o manejo da paisagem, segundo depoimentos de "internautas".

- Unidade do entorno: a imagem da natureza através da vegetação de Mata Atlântica ou o uso das praias predominam na divulgação turística; porém já é possível a percepção de elementos construídos (essencialmente condomínios e resorts) como unidade visual da via.

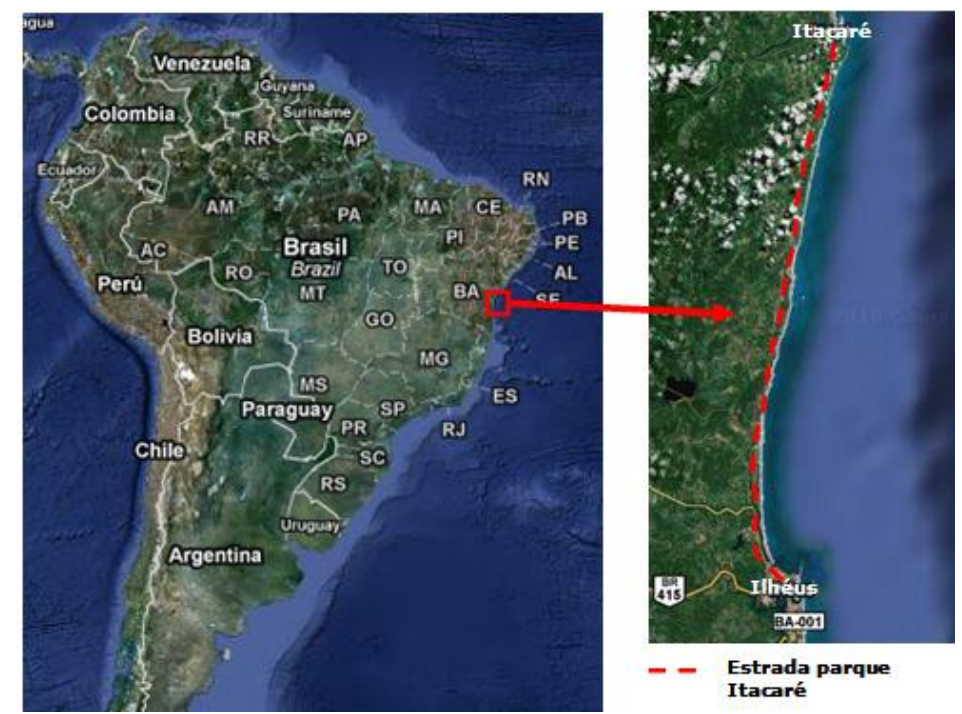

Figura 2. Localização da Estrada-parque Itacaré Fonte: www.googlemaps.com

Equipamentos e mobiliário urbano

- No local foi observada a inexistência de equipamentos como áreas de estacionamentos e recepção para ônibus turísticos e áreas de lazer e recreação. Há apenas dois locais (exceto hotéis e pousadas) considerados como mirantes para a contemplação da paisagem; não há estrutura suficiente quanto a equipamentos e mobiliário. O mobiliário não apresenta padronização e é insuficiente em relação à utilização.

Sinalização/Comunicação visual

- São poucas as ocasiões de sinalização, e na maioria das vezes estão relacionadas aos serviços de hotelaria e turismo; não apresentando padronização, com falta em locais necessários (Figura 3).

Fauna e flora

- A faixa litorânea é composta por planícies costeiras e cordões arenosos formando restingas, 
associadas a remanescentes bem preservados da Mata Atlântica (Pontos Turísticos da Região, 2010). Com áreas de preservação ambiental, a fauna se apresenta muito rica na região, principalmente com a presença de aves, tornando-se também um atrativo para a fruição do turista (Figura 4).
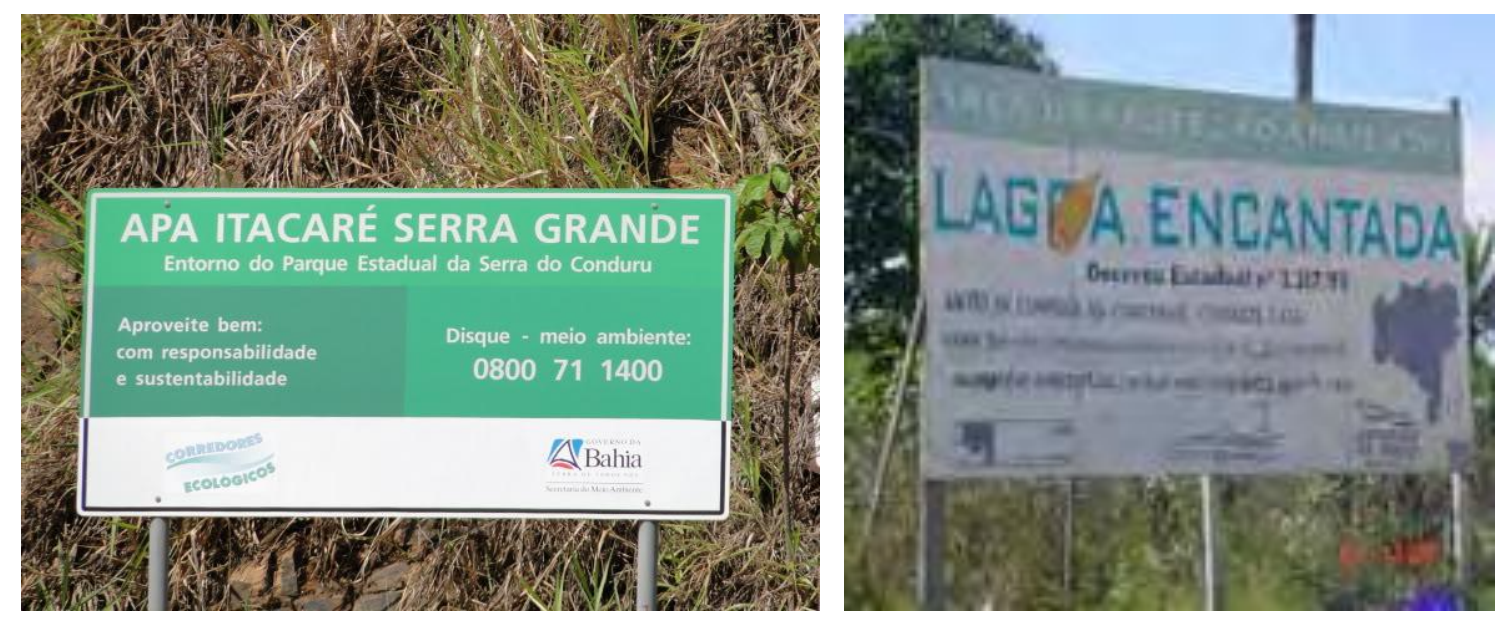

Figura 3. Placas com padrões diferentes de comunicação visual Fonte: http://www.ba.gov.br

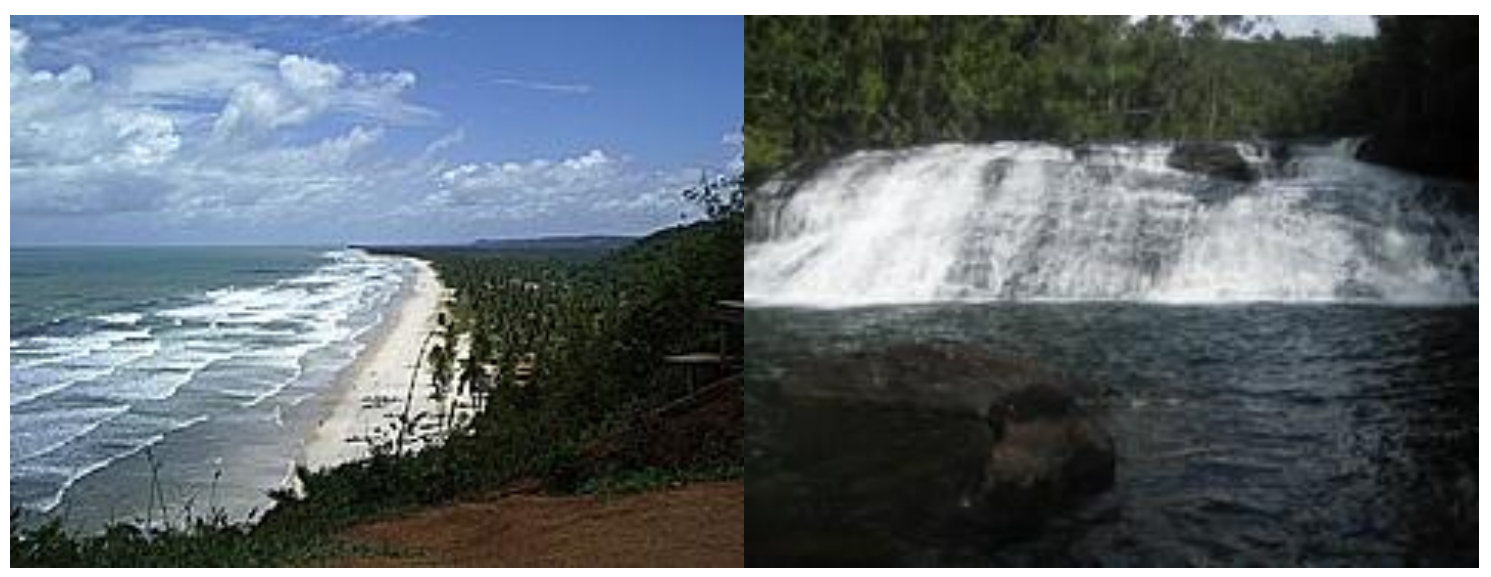

Figura 4. Vista da Serra Grande e cachoeira

Fonte: www.panoramio.com

\section{Serra da Cantareira (SP, Brasil)}

O Parque Estadual Serra da Cantareira foi decretado como tal no final do século XIX por ser uma das maiores florestas urbanas nativas do mundo (com oito mil alqueires). Em 1994 a região da Serra da Cantareira foi reconhecida pela UNESCO como parte da Reserva da Biosfera do Cinturão Verde da Cidade de São Paulo (Beller, 2010). A Figura 5 mostra a localização e a Figura 6, a entrada do Parque. 


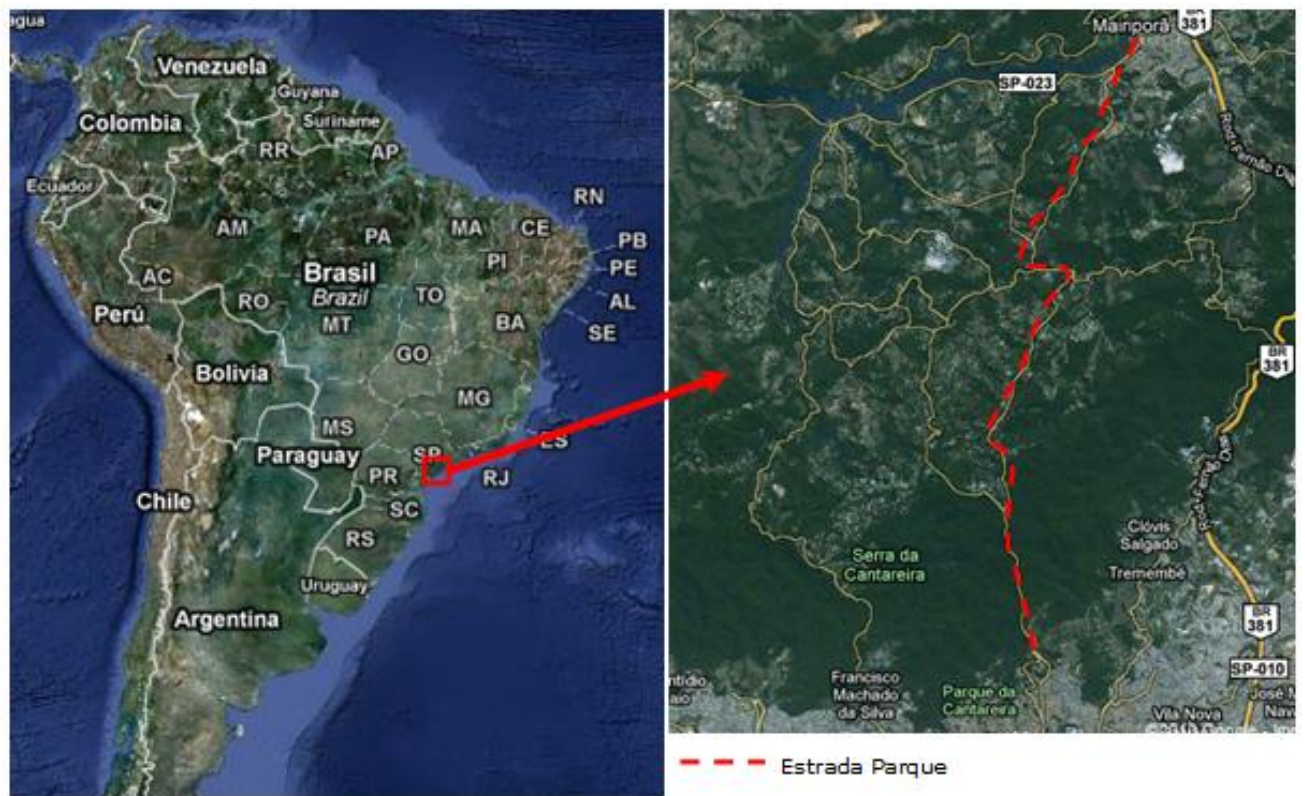

Figura 5. Localização

Fonte: www.googlemaps.com

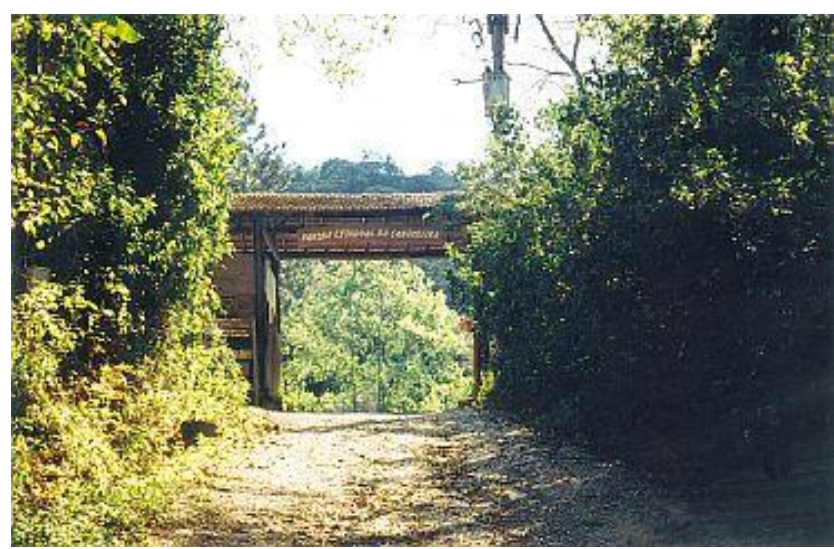

Figura 6. Portal de entrada do parque

Fonte: www.guiadasemana.com.br/Sao_Paulo/Passeios/Estabelecimento/Parque_Estadual_da_Serra_da_Cantareira

\section{Entorno}

- Polos geradores de tráfego: a estrada possui bares e muita diversidade de usos nos finais de semana; mesmo não possuindo passeios públicos, ciclo faixas ou ciclovias. Há uma continuação da estrada como acesso ao núcleo Engordador através de uma via secundária (Conde, 2007).

- Usos: o primeiro espaço aberto ao público foi o núcleo Pedra Grande com a Trilha das Figueiras, Trilha da Bica e Trilha da Pedra Grande. O núcleo Engordador também possui três trilhas: da Cachoeira, do Macuco, e para os esportistas de aventura, a Trilha de Mountain Bike 
com 1,4 km de percurso variando de leve a íngreme. O núcleo Águas Claras está direcionado para educação ambiental, onde é possível percorrer a Trilha das Águas Claras; Trilha da Samambaia-Açú, com caminhada de 1,2 km por uma alameda de samambaias que chegam até 2,5 m de altura; Trilha das Araucárias com 1,2 km de percurso de pinheiros-do-paraná; Trilha Suçuarana com $1,2 \mathrm{~km}$, e que tem esse nome em homenagem a suçuarana, maior felino encontrado no Parque Estadual da Cantareira. Ainda nos arredores do parque podem ser encontradas atrações como tirolesa, cavalgadas, escaladas em rocha, passeios em veículos tração $4 \times 4$, um rapel que pode ser feito em paredões de até $96 \mathrm{~m}$ de altura. Possui um centro de visitantes com playground na entrada, garantindo uso para crianças (Parque Estadual da Cantareira, 2010).

- Transporte: por se tratar de uma região metropolitana, o transporte coletivo de acesso à estrada está garantido, ainda que com baldeações, conexões e intermodalidades.

- Permeabilidade e acessibilidade: o acesso só é possível através de transporte coletivo ou carros de passeio; não há sistema de ciclovias ou ciclo faixas que se integre à estrada. Pode-se considerar a área pouco permeável uma vez que as malhas urbanizadas das cidades que compõem a região metropolitana de São Paulo e que encerram o Parque Estadual da Cantareira não "tangenciam" efetivamente a estrada-parque.

- Unidade do entorno: predomina a imagem da natureza do bioma Mata Atlântica. Pode-se interpretar que a diversidade de usos atrelada à natureza existente confere um ambiente codificado de parque urbano, com uma animação por usos ocasionados pela presença de visitantes.

Equipamentos e mobiliário urbano

- Nota-se uma predominância na linguagem do design dos equipamentos, bem como uma diversidade deles apropriada para usos de parque. A iluminação possui uma padronização, mas se encontra apenas junto aos equipamentos; disto decorre que os usos noturnos podem ser prejudicados ao longo da estrada, porém este fato também faz com que a população de aves não fique afugentada ao longo do percurso.

Sinalização e Comunicação visual

- Ao longo da via existem placas informativas que dizem respeito às localidades e setores, assim como placas que informam a respeito de aspectos geográficos relevantes. Há quantidade suficiente de informação em placas para a legibilidade dos percursos e localização (Figura 7).

Fauna e flora

- A vegetação é predominantemente de Mata Atlântica. Observa-se que em alguns trechos do trajeto a vegetação nativa foi substituída por vegetações mais rasteiras com o intuito de criar visuais interessantes, enquadramentos para morros. Ao longo do percurso é possível ser tomado pela surpresa de animais, portanto um atrativo principalmente para crianças. 
Cabe agora, para encaminhamentos de resultados desta pesquisa, comparar a propaganda turística feita por meios digitais da internet de estradas-parque do exterior com os casos brasileiros. Para tanto, serão levantadas aqui a Romantische Straße (Estrada Romântica) na Alemanha e a estrada-parque no Vale do Rio Don no Canadá dentre outras que foram analisadas nesta pesquisa. Vale notar que a quantidade da informação, bem como a qualidade de material iconográfico coletado para análise nos casos estrangeiros é muito mais significativa que dos casos brasileiros.
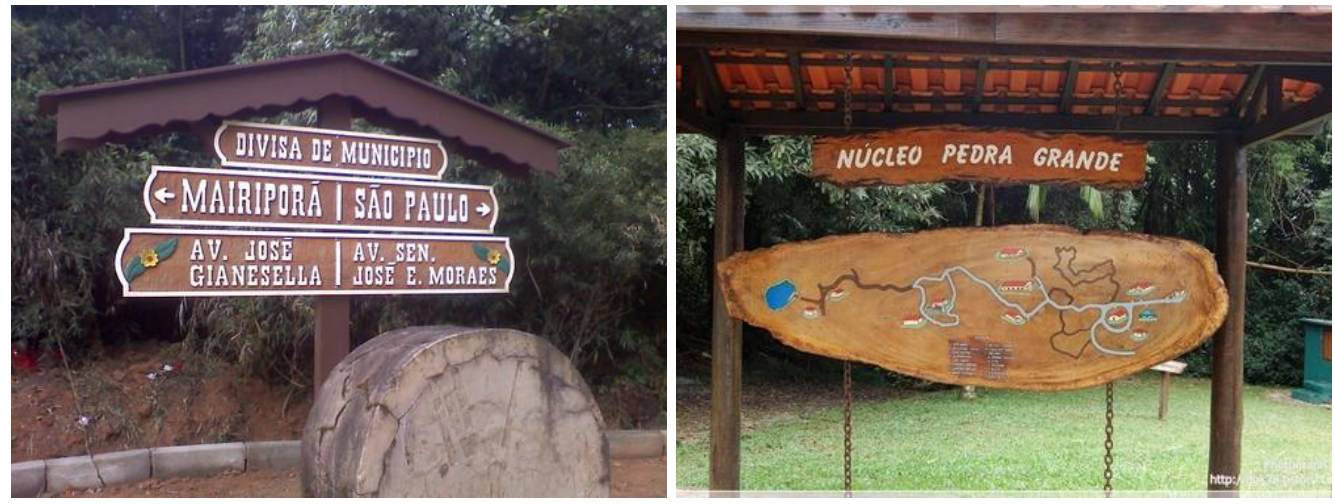

Figura 7. A linguagem "rústica" utilizada nas placas de identificação dos locais é bastante condizente com a linguagem arquitetônica

Fonte: www.comunidadebancodoplaneta.com.br

Deve-se notar ainda que nestes dois casos estrangeiros o tamanho do percurso da estradaparque é maior que nos casos brasileiros. De maneira que a influência regional é muito mais expressiva do que o aspecto local da via. Disto decorre que a quantidade de polos geradores de tráfego, usos do solo e turístico, acesso por transporte coletivo, permeabilidade e acessibilidade são efetivamente mais eficazes, considerando-se também as condições de infraestrutura das realidades alemã e canadense.

\section{Estrada Romântica (Alemanha) e Estrada-parque do Vale do Rio Don (Canadá)}

A Estrada Romântica foi assim denominada por agentes de viagem a partir da década de 1950, localizada entre as regiões da Baviera e Baden-Württemberg, com trajeto entre as regiões de Würzburg a Füssen, contando um total de $350 \mathrm{~km}$ de extensão (Figura 8). Há várias cidades medievais turísticas ao longo das duas regiões, tais como Rothenburg-ob-der-Tauber e Schwangau, além de comércio local e castelos como o Neuschwanstein (Figura 9).

A Estrada Romântica não é uma rodovia, é uma rota cênica para veículos de passeio, pois conta também com uma via alternativa para transporte de cargas ou trânsito rápido. Apresenta ciclovia em toda a sua extensão, bem como oferece pacotes turísticos especiais para ciclistas. 0 Europa Bus Estrada Romântica liga diariamente as cidades membro da rota turística em ambos os 
sentidos da estrada (Estrada Romântica da Alemanha, 2010).

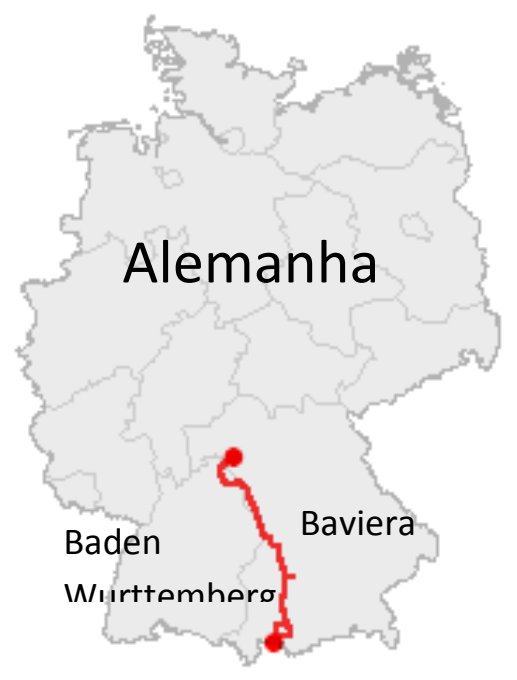

Figura 8. Localização da Estrada Romântica Fonte: www.da.wikipedia.org

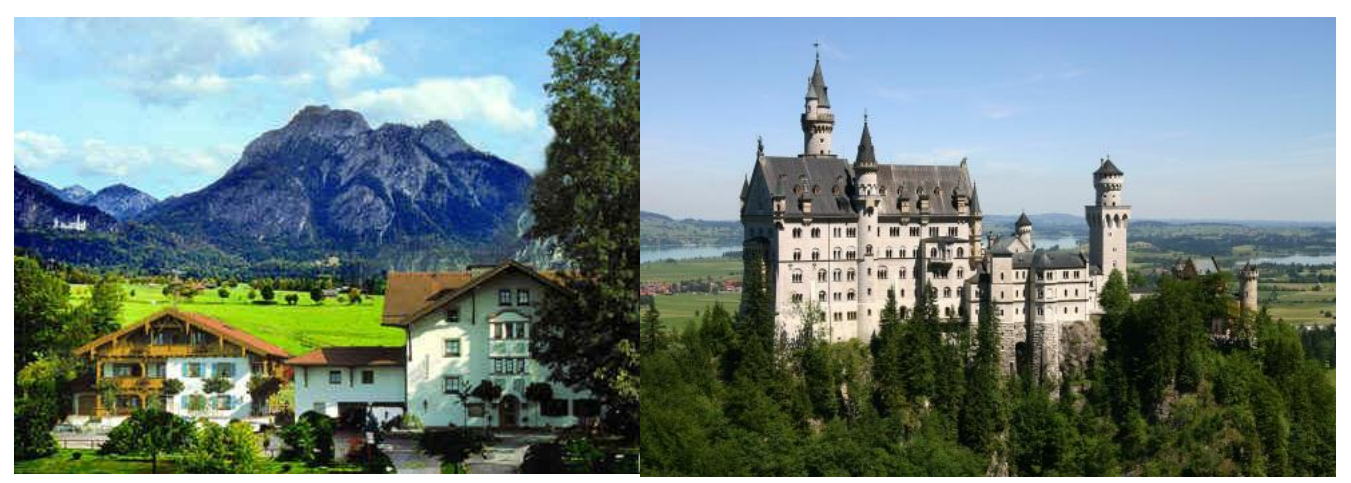

Figura 9. Vista de Schwangau (à esquerda) e do Castelo de Neuschwanstein (à direita) ao longo da Estrada Romântica

Fontes: http://www.adventure-travel.org.uk/img/Schwangau.jpg e www.efenem.files.wordpress.com/2008/02/castleneuschwanstein.jpg

A estrada-parque no Vale do Rio Don no Canadá (Figura 10), além de percorrer um trajeto essencialmente marcado por uma unidade de entorno rural, também possui traçado que adentra malhas urbanizadas, de modo que há uma preocupação de um desenho, programa e gestão do espaço da estrada que viabiliza a conexão de uma via expressa intermitente com áreas urbanas.

A estrada se configura como um parque linear que tem acessos em vários pontos (Figura 11). O parque possui uma trilha paralela ao curso do Rio Don; a pavimentação asfáltica e a largura de cerca de 3,5 m permite que este trecho também possa ser utilizado por ciclistas. Pontes fazem a conexão entre os dois lados do Rio Don. A estrada-parque engloba efetivamente duas vias de alto movimento (Don Valley Parkway e Bayview AV) e duas linhas ferroviárias. O fato de estar 
localizada junto a antigas instalações industriais fez com que a forma do traçado, principalmente para transeuntes, fosse criada a partir dos edifícios existentes dentro da sua área urbanizada, e em conformidade com as vias adjacentes, ferrovias e percurso do Rio Don. Passarelas permitem que os pedestres atravessem a rodovia com segurança (Bonnell, \& Fortin, 2010).

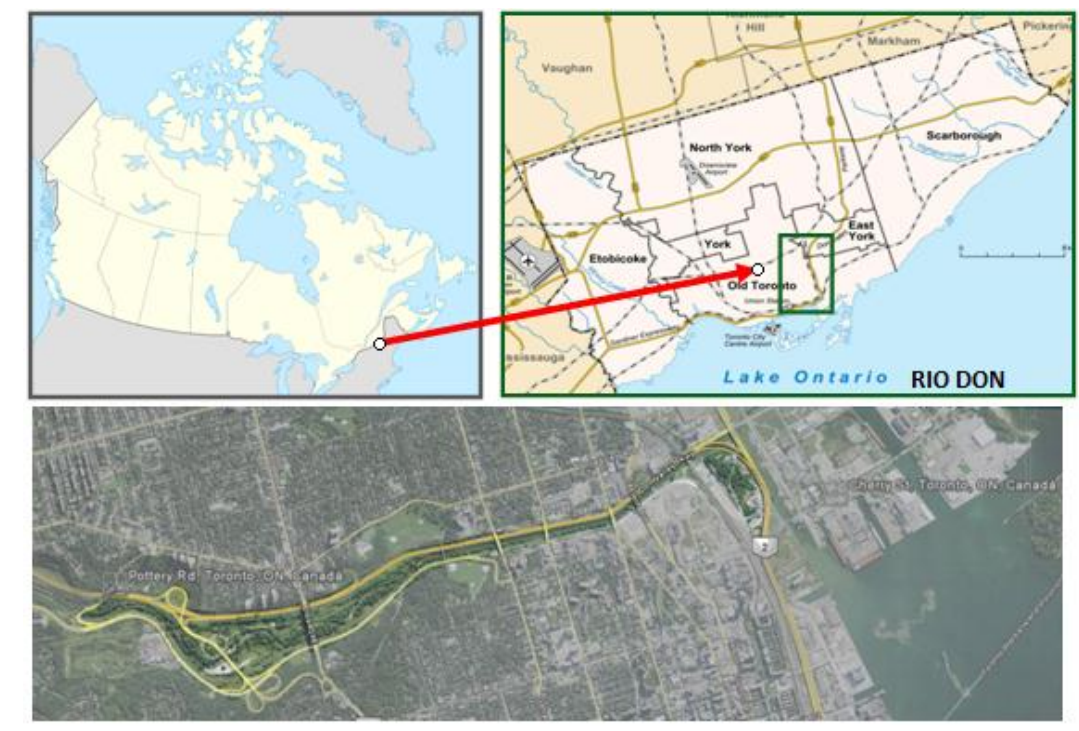

Figura 10. Localização da Estrada-parque do Vale do Rio Don Fonte: www.googlemaps.com

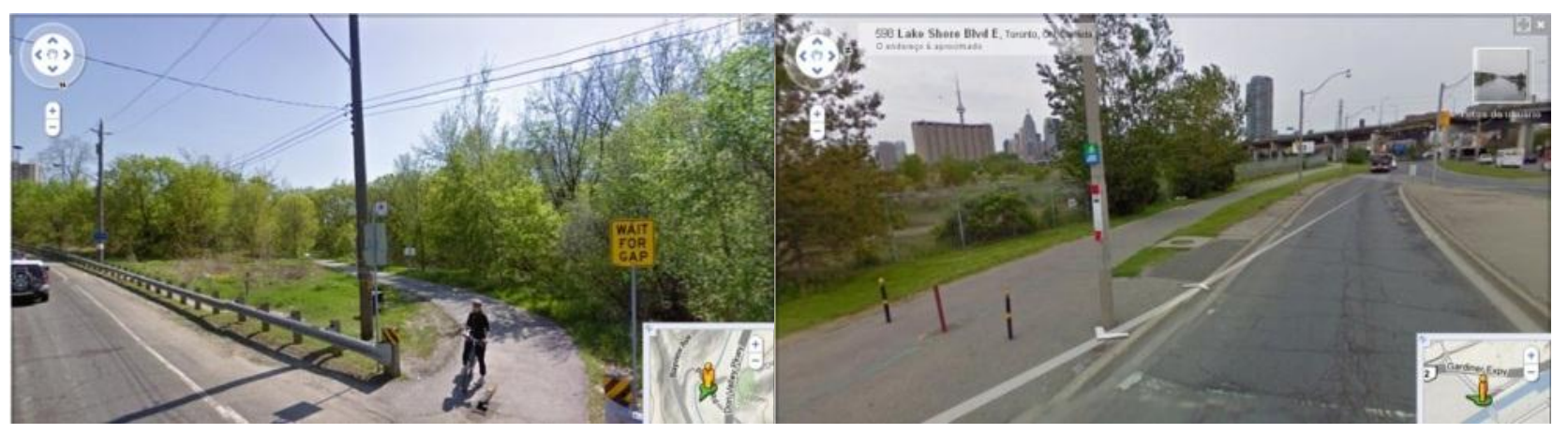

Figura 11. Acesso pela Pottery St. (à esquerda) e pela Cherry St. (à direita) à via Parque no Vale do Rio Don Fonte: www.googleearth.com

Pode-se ressaltar que na análise de textos e imagens dos sites de divulgação turística da estrada-parque do Vale do Rio Don se percebe uma ênfase no fato desta área ter sido no passado uma zona industrial que degradou o meio natural, mas que hoje está recuperada (também) em virtude de uma vontade da ação antrópica. Ou seja, há um valor conferido à propaganda do turismo em vincular e comunicar o desejo daquela sociedade no poder de recuperação ambiental, tratando-se de um fator social que também traz virtudes para a experiência do turista com interesses ambientalistas. 
Os fatores de infraestrutura, equipamentos, mobiliário urbano, sinalização e comunicação visual denotam as diferenças entre os casos brasileiros e os estrangeiros tratados aqui. Quanto à distribuição, quantidade, qualidade, adequação, unidade da linguagem visual e do design, os casos do exterior estão em vantagem aos brasileiros. Se a linguagem do espaço público está de certa forma codificada por estas condições analisadas neste roteiro aqui elencado (entorno, equipamentos e mobiliário urbano, sinalização/comunicação visual, fauna e flora), vale considerar que as estradas-parque no Brasil ainda não se configuram como suportes adequados ao lazer, ócio e turismo como assim se pretende. Mesmo que haja avanços em termos dos encaminhamentos de uma legislação ambiental (inclusive nas diversas instâncias municipais, estaduais e federal) em comparação com os casos estrangeiros, os aspectos espaciais da realidade devem ser revistos e considerados pelos agentes que procuram promover as estradas-parque no Brasil.

Mas é no fator da fauna e da flora que se podem despontar em vantagem os casos de estradas-parque no Brasil. Este fator se constitui em grande potencialidade para os usos turísticos. Nos casos canadense e alemão analisados, verifica-se que a presença da vegetação é essencialmente rasteira com algumas massas arbustivas e árvores de porte esparsas.

Por fim, deve-se considerar que a metodologia de análise a partir de sites de divulgação turística foi relevante para a pesquisa uma vez que constitui (talvez) um primeiro momento de busca a informações pelo turista; portanto, pode contribuir no "alimento" do imaginário e da imaginação necessários à fruição do turismo; a internet pode encerrar também valores de acessibilidade popular ao vislumbre de uma vontade pela viagem turística.

\section{CONSIDERAÇÕES FINAIS}

O exercício comparativo das estradas-parque no Brasil com os casos estrangeiros leva à interpretação de que há diferenciações entre elas, essencialmente na dotação de infraestrutura e equipamentos para os usuários e turistas. Neste caso, as estradas-parque estrangeiras parecem estar mais equipadas que no caso brasileiro. Porém, quanto à oferta de espaços livres com vegetação (como dado paisagístico de fruição visual), as estradas brasileiras estudadas apresentam grande potencial a ser considerado, portanto um patrimônio natural ambiental já existente a ser aproveitado; ao contrário dos casos estrangeiros onde se percebe a escolha de traçados e roteiros a partir de um patrimônio cultural construído, seja de importância arquitetônica vernacular e/ou de significado histórico, como monumento.

De modo que as próprias representações da propaganda turística dos casos brasileiros de estradas-parque denotam a apropriação da natureza como fator de experiências turísticas, incluindo um processo dialético em que o próprio turismo salvaguarda seu meio, porque é dele seu "valor agregado" como fonte de renda, emprego, entre outros.

As diferenças dos casos estudados no Brasil e no exterior ainda vão desde o que a estradaparque representa para a cidade ou região, até como ela é vista pelos órgãos públicos. No Brasil a estrada-parque ainda não tem nenhum instrumento que a regule ou até mesmo que assegure 
alguns de seus parâmetros, o que se deve preservar ou conservar e que principalmente incentive o seu uso. Ela também pode ser interpretada apenas como uma via de passagem onde se "admira" a natureza, porém não apresenta a infraestrutura necessária para que ela se efetive.

A estrada-parque pode se apresentar como implementação (até mesmo financiadas pelo Estado) de uma via com condições carroçáveis apenas para o escoamento de produção das propriedades contíguas à estrada-parque. Bem como pode influenciar na especulação imobiliária principalmente de regiões turísticas, caso evidente de Itacaré na Bahia.

Por fim, considerando o método interpretativo onde o a linguagem do espaço é plurisignificativa, conclui-se que é a partir deste espaço específico dos casos brasileiros que se podem sugerir padrões para as nossas estradas-parque; é a partir do espaço empírico local que se constrói a generalização possivelmente como contribuinte para implantação de uma legislação específica como unidade de conservação da estrada-parque, para além de apenas referenciais estrangeiros já codificados e signos já generalizados e conceituados. Os casos brasileiros já demonstram a exuberância da natureza como premissa existente de fruição e deleite visual, portanto a natureza já é um "bem edificado" sem custos para o poder público; daí por diante a vantagem inclusive de corredores verdes ecológicos necessários e atrelados às estradas-parque.

\section{REFERÊNCIAS}

Beller, A. (2010). Serra da Cantareira. Recuperado em 29 junho, 2010, de <http://charmeaovolante.uol.com.br/canais/turismo/interna.php?id_canal=70materia=SerradaCantareira.

Bonnell, J., \& Fortin, M. Don Valley Historical Mapping Project Background. Recuperado em 24 julho, 2010, de http://maps.library.utoronto.ca/dvhmp/.

Conde, C. A. dos R. (2007). Estrada Parque: Estratégia de desenvolvimento sustentável, o caso da estrada parque na Serra da Cantareira. Dissertação de mestrado, Pontifícia Universidade Católica de Campinas, Campinas, SP, Brasil.

Esportes e Lazer (2010). Recuperado em 22 junho, 2010, de http://www.itacare.com/itacare/megabusca.php?group=ecotrip\&cat=trilha +cachoeira\&lang=portugues.

Estrada Parque Pantanal. Recuperado em 15 junho, 2010, de http://www.webventure.com.br/destinoaventura/destinos/index/atracoes/destino/corumba/atr/395.

Estrada Parque Pantanal. Recuperado em 15 junho, 2010, de http://www.riosvivos.org.br/canal.php?mat=14659.

Estrada Parque Pantanal. Recuperado em 16 junho, 2010, de http://blogandoturismo.googlepages.com/CAPTULOII.PDF.

Estrada Romântica da Alemanha. Recuperado em 4 julho, 2010, de www.rodgerrealm.com/germany.

Franco, M. A. de R. (1997). Desenho ambiental: uma introdução à arquitetura da paisagem com o paradigma ecológico. São Paulo, SP: Annablume.

Geisendorf, T. Serra da Cantareira - SP. Recuperado em 29 junho, 2010, de http://www.ecoturismobrasil.com.br/serra_da_cantareira_3.htm. 
Kliass, R. G. (1993). Parques urbanos de São Paulo. São Paulo, SP: Pini Editora.

Macedo, S. S., \& Sakata, F. G. (2010). Parques urbanos no Brasil. São Paulo, SP: EDUSP.

Parque Estadual da Cantareira. Recuperado em 29 junho, 2010, de http://turmadoarboreto.blogspot.com/2007/12/parque-estadual-da-cantareiraa-maior.html.

Parque Estadual Serra da Cantareira. Recuperado em 30 junho, 2010, de http://www.guiadasemana.com.br/Sao_Paulo/Passeios/Estabelecimento/Parque_Estadual_da_Serra_da_C antareira. .aspx? id $=1151$.

Peirce, C. S. (1975). Semiótica e filosofia. São Paulo, SP: Cultrix/EDUSP.

Pontos Turísticos da Região. Recuperado em 22 junho, 2010, de http://www.elkaris.com/?pg=14\&keys=Itacare+Pontos+ Turisticos\&t=1258.

Projeto Estrada Parque da Roseira. Recuperado em 30 junho, 2010, de http://www.recanta.org.br/estrada_parque.html.

Raposo, I., \& Heredia, C. Shopping na Cantareira: progresso indesejável. Recuperado em 29 junho, 2010, de http://www.jornaldaserra.com.br/8Arquivo/SHOPPING/1shoppingpage.htm.

Romantische Strasse. Recuperado em 4 julho, 2010, de http://romantischestrasse.de/.

A Rota Romântica é 60. Recuperado em 4 julho, 2010, de http://magazin.outdooractive.com/de/2010/03/22/die-romantische-strase-wird-60/.

Santos, M. (1996). A natureza do espaço: técnica e tempo, razão e emoção. São Paulo, SP: Hucitec.

Soriano, A. J. S. (2006). Estrada Parque: Proposta para uma definição. Tese de doutorado, Universidade Estadual Paulista, Rio Claro, SP, Brasil.

Toronto. Recuperado em 5 julho, 2010, de www.toronto.ca/don.

Ururuça/Serra Grande. Recuperado em 19 junho, 2010, de

http://www.costadocacau.com.br/pt/c_serragrande.php. 